\title{
Orações adverbiais introduzidas pelos transpositores sem/sem que: relação entre a ordem da oração satélite e os propósitos comunicativos
}

Adverbial clauses introduced by the transpositors sem/sem que (without/unless): the relation between the order of the satellite clause and communicative purposes

Marta Anaíza Bezerra Ramos ${ }^{1}$, Camilo Rosa Silva²

Doutora em Linguística, Professora da Universidade Estadual da Paraíba (UEPB), membro do Grupo de Pesquisa Investigações Funcionalistas (GIF).

martaanaisa@gmail.com

Doutor em Letras, Professor do Programa de da-Graduçao em Linguistica (PROLING) líder do Grupo de Investigacões Funcionalistas (GIF).

camilorosa@gmail.com
RESUMO: A relação entre a ordem e as funções textual-discursivas das orações satélites introduzidas pelos transpositores sem/sem que é o ponto de reflexão deste artigo. Procuramos mostrar que fatores de ordem cognitiva (facilidade de compreensão), textual (estabelecimento da coesão e da coerência) e comunicativa (subjetividade/argumentatividade) influenciam as escolhas dos usuários da língua, aspecto que revela a existência de motivação icônica no processo de organização dos períodos. Destacamos, também, as funções das orações parentéticas, tendo em vista seu caráter avaliativo, que é uma marca dos textos argumentativos.

PalAVRAS-CHAVE: Orações adverbiais; ordem; fluxo informacional; funções textual-discursivas.

ABSTRACT: This article intends to analyze the relationship between order and textual-discursive functions of satellite clauses introduced by transpositors sem/sem que. We have attempted to show that cognitive, textual and communicative factors influence the speakers' choices. We therefore consider aspects such as ease of understanding, establishment of cohesion/coherence and subjectivity/argumentation that reveal the existence of iconic motivation in the process of sentence organization. We also highlight the functions of parenthetical clauses, keeping in view of its evaluative character, which is a mark of argumentative texts.

KEYwORDS: Adverbial clauses; order; flow of information; textual and discursive functions. 


\section{Introdução}

$\mathrm{N}$ este artigo, propomo-nos a tratar da ordenação de orações adverbiais introduzidas pelos transpositores sem/sem que, objetivando mostrar que sua disposição nas posições anteposta, intercalada e posposta em relação à matriz tem relação com o estatuto informacional (informação velha, nova, inferível) como também com as funções textual-discursivas por elas assumidas. Subjaz a essa proposta um princípio que constitui um dos pontos unificadores das várias tendências no quadro geral da teoria Funcionalista - o de que a estrutura sintática, ou o produto da atividade linguística, serve de âncora para a depreensão das motivações semânticas e discursivas de uma determinada estrutura, ou seja, lidamos, aqui, com a interface sintaxe/ semântica/discurso/pragmática.

Para os funcionalistas, a gramática integra sentido e estrutura linguística, estando o sentido condicionado às funções comunicativas. O estudo da língua, sob essa perspectiva, deve levar em consideração a interação entre os componentes formal, funcional, pragmático e discursivo ${ }^{1}$, tendo em vista que na realização/materialização linguística, é difícil estabelecer fronteiras entre a sintaxe e a semântica, e entre estas e os efeitos de sentido produzidos.

As orações ora tomadas como objeto de estudo participam do mecanismo de articulação denominado hipotaxe adverbial. Tratam-se de estruturas que envolvem a combinação de elementos de natureza distinta, mas em que não há encaixamento, estando uma oração em relação de adjunção com outra, servindo-lhe para adicionar uma informação ou circunstância. Tais orações estabelecem, pois, relações lógico-semânticas. Cumpre destacar que

\footnotetext{
${ }^{1}$ É oportuno destacar, citando Castilho (2010), que a distinção entre o ponto de vista funcional e o do modelo proposto por esse autor, o da gramática funcional cognitivista, situa-se no fato de que, se para sintático o output no nov mistema não há hie e discursivo funciona o outro, por serem independentes.
}

essas orações, se comparadas às substantivas e adjetivas restritivas, têm uma ligação mais fraca em relação à matriz, mas, de outro modo, são mais suscetíveis às necessidades do discurso, como assinala Castilho (2010). Por isso, considerando-se os parâmetros universais de dependência/ independência sintática propostos para diferenciar os processos de coordenação/subordinação, aliados ao critério de encaixamento, as adverbiais se situam entre as coordenadas e as subordinadas.

As orações adverbiais, na visão de Decat (2001, p. 106), apesar de aparentarem ser encaixadas, têm "mais que uma função gramatical, uma função discursiva, no sentido de orientar o ouvinte para a mensagem que se quer transmitir, organizando, assim, a forma do discurso". Por essa razão é que, numa perspectiva funcionalista, o estudo desse mecanismo de combinação oracional - a hipotaxe - ultrapassa a identificação do tipo de informação que é adicionada à oração matriz por meio da associação à tipologia de advérbios. No que diz respeito à ordem, a autora afirma que dois fatores podem determinar a ordenação dos elementos em relação núcleosatélite: i) o tipo de relação que emerge da combinação das orações matriz e adverbial; e ii) a função discursiva da oração adverbial.

Para a reflexão aqui proposta, optamos por aliar a exposição teórica à exploração dos dados, tentando articular nessa junção a análise funcional. Para atingir tal intento, organizamos a exposição em duas seções. Na primeira, discorremos sobre a relação entre o fluxo informacional e a ordem dos constituintes na sentença. Na segunda, destacamos o papel das orações adverbiais (ou satélites adverbiais ${ }^{2}$ ) na organização discursiva, apontando as funções textual-discursivas por elas assumidas. Abordamos, ainda, o funcionamento das orações parentéticas, consideradas orações formalmente independentes, tomando como parâmetro a noção de unidade informacional.

2 As orações adverbiais são também denominadas "satélites" ou "adendo", por estarem em relação de adjunção com outra (a matriz), servindo-lhe para adicionar uma informação ou circunstância. 
A amostra selecionada para a presente discussão compreende 77 (setenta e sete) estruturas oracionais introduzidas pelos transpositores sem e sem que, coletadas em textos da esfera jornalística - artigos de opinião (A), entrevista (E), carta ao leitor (CL)/editoriais (Edit.) - gêneros veiculados nos periódicos semanais Veja, Época e Isto É. Essa amostra representa um recorte de $20 \%$ de um corpus mais amplo, constituído de 367 (trezentos e sessenta e sete) estruturas oracionais coletadas em exemplares dos anos 2011 e 2012. No quadro a seguir, descriminamos como estão distribuídos os dados:

Quadro 1 - Configuração dos dados

\begin{tabular}{|l|l|}
\hline $\begin{array}{l}\text { RECORTE DE 20\% DOS DADOS } \\
\text { (77 estruturas oracionais) }\end{array}$ & $\mathbf{1 3} \rightarrow \begin{array}{l}\text { introduzidas pela locução SEM QUE } \\
\text { (desenvolvidas) }\end{array}$ \\
& $\mathbf{6 4} \rightarrow \begin{array}{l}\text { introduzidas pela preposição SEM } \\
\text { junto a forma verbal infinitiva (reduzidas) }\end{array}$ \\
\hline
\end{tabular}

Para atender aos propósitos deste estudo, orientamo-nos nos postulados de Paiva (1997), Azevedo (2002), Pezatti (1994; 2005), Decat (2011), Neves (1999/2008), entre outros.

\section{Fluxo informacional e ordenação}

Estudar a oração sob a perspectiva discursiva é estudá-la inserida no texto. Essa premissa deu sustentação a estudos em duas diferentes direções, como indica Castilho (2010): uma voltada para a verificação do processamento de informação na sentença; e outra, para o estudo da tipologia das sentenças, uma vez que elas representam atos de fala. Especificamente em relação à primeira vertente, o conceito de processamento de informação é tomado como parâmetro para a explicação de fenômenos linguísticos como pronominalização, deslocamento de constituintes, sujeitos sentenciais. A base desse conceito, afirma Paiva (1997), está na crença de que existe um isomorfismo entre organização do conteúdo de orações e os objetivos da transmissão de informações, tese que se originou no círculo dos linguistas da Escola de Praga. Uma designação mais ampla atribuída a esse modelo de abordagem é Perspectiva Funcional da Sentença (PFS), a que se somam, segundo Pezatti (2005, p. 176): “'organização contextual da sentença', 'temarema' e 'estrutura tópico-comentário'”.

Conforme esse modelo de análise ${ }^{3}$, a sentença é caracterizada como tendo duas partes - uma que apresenta a noção inicial, o ponto comum ao falante e ao ouvinte, e a outra que representa o objetivo do discurso, ou a informação que o locutor intenta compartilhar com o interlocutor. Advém dessa noção preliminar a segmentação da sentença em tema e rema proposta por Mathesius. Para esse autor, os meios lexicais e gramaticais se acomodam na sentença conforme o contexto de enunciação os exija, de modo que, sob o aspecto gramatical, a sentença se desmembra em sujeito e predicado, estando a divisão entre tema e rema vinculada ao plano comunicativo. Essa visão converge com a de Danes (1957, apud FIRBAS, 1974), para quem a análise sintática se realiza em três níveis - o semântico, o gramatical e o da organização da sentença. O primeiro delimita, na sentença, qual a AÇÃO e os participantes na posição de AGENTE e OBJETO; o segundo especifica SUJEITO, VERBO e OBJETO; e o terceiro identifica TEMA-TRANSIÇÃO-REMA.

Firbas (1974) amplia esse modelo, incluindo, no plano comunicativo, o princípio do dinamismo comunicativo (DC), definido como "a extensão com que determinado elemento lingüístico contribui para o desenvolvimento da comunicação." (PEZATTI, 2005, p. 178). Segundo o autor, o processo

3 De acordo com Pezatti (2005, p. 177), as pesquisas vinculadas à Perspectiva Funcional da Sentença foram impulsionadas, na antiga Checoslováquia, por Vilém Mathesius (1882-1945); mas é de Henri Weil a autoria do trabalho pioneiro nessa área, intitulado De l'ordre dês mots dans les langues anciennes comparées aux langues modernes. 
comunicativo obedece ao mesmo princípio básico que rege a organização da sentença - a linearidade, mecanismo que determina que a ordem gramatical tende a refletir a ordem natural dos fatos da realidade extralinguística, o que não significa que a ordem não possa sofrer alteração. Assim, o dinamismo comunicativo se revela no sentido de que a informação em posição inicial apresenta menor grau de informatividade, seguindo-se de informação como maior grau de informatividade. Mas, na sua visão, não há, necessariamente, uma correlação entre Tema e informação velha, o que vai de encontro à posição de Danes, para quem é viável tal correspondência, já que o Tema quase sempre expressa informação velha. Outra divergência entre a posição de Danes e a de Mathesius e Firbas, segundo Paiva (1997), diz respeito ao fato de os dois últimos tomarem como objeto de estudo a frase, enquanto o primeiro considera que a distribuição da informação determina a organização dos enunciados no texto, ou seja, ultrapassa o nível da frase.

Embora tenha sido originada na Escola de Praga, a Perspectiva Funcional da Sentença também encontra espaço na Escola de Londres, tendo Halliday (1974) como um dos adeptos que lhe concede um lugar na descrição linguística. Na visão desse autor, o sistema linguístico compreende um conjunto de componentes funcionais que têm correspondência com três macrofunções: a ideacional, a textual e a interpessoal. A função textual, particularmente, diz respeito àquela que permite a criação de um texto, sendo a sentença concebida como uma mensagem. Halliday menciona ainda um outro sistema formado por componentes que integram uma gramática de mensagens, quais sejam: o status da oração e suas unidades de comunicação, razão de a sentença envolver unidades sintáticas e unidades comunicativas. As unidades sintáticas materializam-se na sentença, oração e sintagma; e as comunicativas, na estrutura informacional, estabelecendo a distinção entre dado e novo, noções que só podem ser delimitadas considerando-se a situação ou texto precedente.
A mobilidade posicional é uma característica das orações adverbiais, herdada do advérbio, mas sabemos que há algumas restrições a essa flutuação distribucional. Antes de apontar as motivações que podem determinar a colocação das orações que constituem o objeto de análise, convém situá-las quanto à ordem de ocorrência em relação à matriz. Da análise do corpus, identificamos a posição posposta como a preponderante, independentemente de as orações adverbiais se apresentarem sob a estrutura reduzida ou desenvolvida.

Por entendermos que o modelo estrutural não é um parâmetro condicionante da ordenação, os dois padrões oracionais são avaliados paralelamente. Nas Tabelas 1 e 2 abaixo, especificamos o número de ocorrências das estruturas reduzidas e desenvolvidas, conforme as três possibilidades de ordenação.

Tabela 1 - Distribuição das orações reduzidas conforme a ordem de ocorrência

\begin{tabular}{l|c|c|c|c|}
\hline \multirow{2}{*}{ Revistas } & \multicolumn{3}{|c|}{$\begin{array}{c}\text { Orações reduzidas } \\
\text { [SEM + [...] + INFINITIVO) }\end{array}$} & Total \\
\cline { 1 - 5 } & Posposta & Anteposta & Intercalada & \\
ÉPOCA & 105 & 10 & 2 & $\mathbf{1 1 7}$ \\
ISTO É & 97 & 10 & 8 & $\mathbf{1 1 5}$ \\
Total & 73 & 6 & 6 & $\mathbf{8 5}$ \\
\hline
\end{tabular}

Tabela 2 - Distribuição das orações desenvolvidas conforme a ordem de ocorrência

\begin{tabular}{l|c|c|c|c}
\hline \multirow{2}{*}{ Revistas } & \multicolumn{3}{|c}{$\begin{array}{c}\text { Orações desenvolvidas } \\
\text { (LOCUÇÃO SEM QUE) }\end{array}$} & Total \\
\cline { 1 - 4 } VEJA & Posposta & Anteposta & Intercalada & \\
ÉPOCA & 18 & 1 & - & $\mathbf{1 9}$ \\
ISTO É & 17 & - & - & $\mathbf{1 7}$ \\
Total & 11 & 2 & 1 & $\mathbf{1 4}$ \\
\hline
\end{tabular}


O predomínio da posposição, nos dois padrões oracionais (desenvolvidas/ reduzidas), provavelmente, foi motivado pelos tipos de relação semântica expressos nas orações em estudo. Dentre os valores expressos por essas orações, destacam-se os de modo, consequência e adição $0^{4}$, que, juntos, somam 169 (cento e sessenta e nove) ocorrências entre reduzidas e desenvolvidas, superando a quantidade de orações pospostas que expressam concessão e condição - 121 (cento e vinte e uma) ocorrências entre reduzidas e desenvolvidas. Esses dois últimos matizes semânticos se mostraram menos produtivos no corpus analisado; por outro lado, embora constituam esferas que permitem a mobilidade, teve preferência a ordem posposta. A anteposição corresponde à segunda alternativa de uso, seguindo-se as estruturas intercaladas, que, normalmente, trazem comentários - esclarecimentos ou avaliação do usuário.

Antes de passarmos à análise qualitativa dos dados, é oportuno expor as Tabelas 3, 4 e 5, nas quais apresentamos a quantificação de ocorrências conforme a classificação semântica. Devemos esclarecer que as duas primeiras tabelas contemplam os dados cuja classificação foi guiada pelo sentido que sobressaiu no contexto, embora reconheçamos que seria possível depreender outro matiz. A Tabela 5 exibe os usos identificados como ambíguos, aqueles em que o leque de interpretação é mais amplo, havendo maior sincretismo de conteúdo, a ponto de se entrelaçarem sentidos de domínios distintos, a exemplo de adversidade/ consequência, nos quais se mesclam as esferas de oposição e causalidade.

Tabela 3 - Ordem de ocorrência das orações reduzidas por categorias semânticas

\begin{tabular}{|c|c|c|c|c|c|c|c|c|}
\hline Ordem & Concessão & $\begin{array}{l}\text { Negação de } \\
\text { Consequência }\end{array}$ & Condição & Modo & Adição & Tempo & Modalizador & Causa \\
\hline \multicolumn{9}{|l|}{ Posposta } \\
\hline VEJA & 27 & 28 & 7 & 22 & 5 & 1 & - & 1 \\
\hline ÉPOCA & 32 & 26 & 9 & 23 & 7 & - & - & - \\
\hline ISTOÉ & 21 & 12 & 4 & 17 & 9 & - & 1 & 1 \\
\hline Total: 253 & 80 & 66 & 20 & 62 & 21 & 1 & 1 & 2 \\
\hline \multicolumn{9}{|l|}{ Anteposta } \\
\hline VEJA & 5 & - & 3 & - & & - & 1 & 1 \\
\hline ÉPOCA & 9 & - & 1 & - & & - & - & - \\
\hline ISTOÉ & 2 & - & 3 & 1 & & - & - & - \\
\hline Total: 26 & 16 & - & 7 & 1 & & - & 1 & 1 \\
\hline \multicolumn{9}{|l|}{ Intercalada } \\
\hline VEJA & 2 & - & - & 1 & & - & - & - \\
\hline ÉPOCA & 4 & - & - & - & & - & 1 & 1 \\
\hline ISTOÉ & 6 & - & - & 1 & & - & - & - \\
\hline Total: 15 & 12 & - & - & 2 & & - & 1 & 1 \\
\hline Geral: 295 & 108 & 66 & 27 & 65 & 21 & 1 & 3 & 4 \\
\hline
\end{tabular}

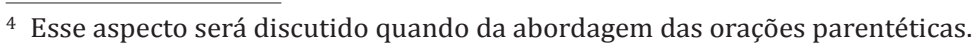


Tabela 4 - Ordem de ocorrência das orações desenvolvidas por categorias semânticas

\begin{tabular}{|c|c|c|c|c|c|}
\hline ORDEM & Concessão & Condição & Consequência & $\begin{array}{l}\text { Negação de } \\
\text { Consequência }\end{array}$ & Modo \\
\hline \multicolumn{6}{|l|}{ Posposta } \\
\hline VEJA & 5 & 2 & 3 & 6 & 1 \\
\hline ÉPOCA & 10 & - & - & 3 & 1 \\
\hline ISTO É & 4 & - & 3 & 2 & 1 \\
\hline Total: 41 & 19 & 2 & 6 & 11 & 3 \\
\hline \multicolumn{6}{|l|}{ Anteposta } \\
\hline VEJA & 1 & - & - & - & - \\
\hline ÉPOCA & - & - & - & - & - \\
\hline ISTO É & 2 & - & - & - & - \\
\hline Total: 3 & 3 & - & - & - & - \\
\hline \multicolumn{6}{|l|}{ Intercalada } \\
\hline VEJA & - & - & - & - & - \\
\hline ÉPOCA & - & - & - & - & - \\
\hline ISTO É & 1 & - & - & - & - \\
\hline Total: 1 & 1 & - & - & - & - \\
\hline Geral: 45 & 23 & 2 & 6 & 11 & 3 \\
\hline
\end{tabular}

Apresentamos primeiramente a classificação das orações reduzidas, seguindo-se a das desenvolvidas. Ressalvamos que, na Tabela 5, constam os resultados nos dois modelos oracionais paralelamente.

Na sequência, apresentamos dois excertos ilustrativos da posposição - o primeiro representando uma relação que pode ser interpretada como consecutiva (noção expressa tanto sob a forma reduzida quanto desenvolvida) e o segundo, a relação modal, casos em que a inversão não é possível.

(1) "A gente está na luta. Mulheres e homens e crianças e jovens, porque um não muda sem mudar alguma coisa no outro, um não sofre nem se alegra sem que algo disso se reflita nos demais. Então, quem sabe a gente não unifica tudo isso, e inventa um Dia da Páscoa?" (VJ, A, 16/03/11)

(2) “[... No reino dos Kirchners, o PCdoB poderia exercer à vontade seu comunismo mercantil, sem que jornalistas abelhudos e invejosos se metessem em seus negócios privados com o dinheiro público". (IÉ, A $31 / 10 / 11)$

Tabela 5 - Ordem de ocorrência das orações reduzidas e desenvolvidas por matizes semânticos (sentido ambíguo)

\begin{tabular}{|c|c|c|c|c|c|c|c|c|}
\hline REDUZIDAS & Concessão/Modo & Concessão/Condição. & $\begin{array}{l}\text { Concessão/Neg. de } \\
\text { Consequência }\end{array}$ & Condição/Modo & $\begin{array}{l}\text { Condição/Neg. de } \\
\text { Consequência }\end{array}$ & DESENVOLVIDAS & $\begin{array}{l}\text { Condição/Neg. de } \\
\text { Consequência }\end{array}$ & $\begin{array}{l}\text { Concessão/Neg. de } \\
\text { Consequência. }\end{array}$ \\
\hline Posposta & & & & & & Posposta & & \\
\hline$V E J A$ & 9 & - & 1 & 1 & 1 & $V J$ & - & 1 \\
\hline ÉPOCA & - & 1 & - & - & 1 & $E ́ P$ & 2 & 1 \\
\hline ISTOÉ & 4 & 1 & 1 & - & - & $I E ́$ & - & 1 \\
\hline Total: 20 & 13 & 2 & 2 & 1 & 2 & Total: $\mathbf{5}$ & 2 & 3 \\
\hline Anteposta & & & & & & Anteposta & & \\
\hline VEJA & 1 & - & - & - & - & VJ & - & - \\
\hline ÉPOCA & - & - & - & - & - & ${ }^{\prime} P$ & - & - \\
\hline ISTO É & - & - & - & - & - & $I E ́$ & - & - \\
\hline Total: 1 & 1 & $\mathbf{0}$ & $\mathbf{0}$ & 0 & 0 & Total: $\mathbf{0}$ & $\mathbf{0}$ & $\mathbf{0}$ \\
\hline
\end{tabular}


No primeiro excerto, de acordo com a opinião do escritor, a mudança, o sofrimento e a alegria ocorridos em um indivíduo contagiam automaticamente os demais. Logo, há uma relação de dependência, de modo que a ordem dos fatos não pode ser alterada. Quanto ao segundo, embora não envolva sequenciação, mas, ao contrário, simultaneidade de fatos, a ordem também não pode ser alterada, em virtude de o segundo enunciado servir para explicar o que se entende por "exercer à vontade seu comunismo mercantil"; logo, trata-se de uma informação complementar àquela expressa anteriormente.

Portanto, a justificativa para a posposição das orações consecutivas e modais é atribuída à motivação icônica ${ }^{5}$, relativa à ordem dos eventos, no sentido de que a enunciação de uma consequência se segue à de uma causa; assim como a descrição do modo como ocorreu um evento ou o esclarecimento sobre um estado de coisas se segue à enunciação desse evento ou estado de coisas. Salientamos, em relação às orações modais reduzidas, que, dentre as 85 (oitenta e cinco) ocorrências, apenas três são ilustrativas de deslocamento - uma oração anteposta e duas intercaladas. Os excertos abaixo ilustram cada uma das posições:

(3) "Foi a única vez que o senhor esteve com o ministro? Não. Houve mais dois encontros. [...] Dedo em riste, sem deixar que eu me explicasse, ele disse que estava mandando cancelar todas as minhas portarias". (IÉ, E, $03 / 08 / 11$ )

(4) “[...] Estamos perdendo a "guerra mundial por empregos" em incrível episódio de "fogo amigo", quando disparamos sem cessar contra nossa 5 A noção de iconicidade remete a uma relação de semelhança entre a estrutura linguística (forma) e o
sentido expresso por ela (função) (MARTELOTTA, 2010). Parte-se da ideia de que, se a linguagem revela
os processos de conceitualização humana e os conceitos são construídos com base na experiência,
então as estruturas linguísticas refletem o modo como a experiência foi organizada na mente. Em se
tratando da ordem das adverbiais em relação à matriz, a motivação pode estar associada à iconicidade lógico-semântica, ou discursiva. própria base produtiva. Empresários e trabalhadores são atingidos por excessivos encargos sociais e trabalhistas, impostos elevados, dólar barato, juros altos e muita burocracia." (IÉ, A, 15/11/10)

A oração reduzida em (3) ilustra a primeira situação. Embora pareça estar isolada, não é o que ocorre - por representar a segunda circunstância em relação à principal, a primeira vírgula a separa do sintagma adverbial inicial, e a segunda, da oração principal. Já em (4), apesar da ausência de vírgulas para isolar a oração intercalada, a oração reduzida corta o predicado: disparamos [...] contra [...].

Passando às orações concessivas, os dados observados corroboram uma conclusão a que chegaram Neves et al. (2008, p. 982) quando da análise de elocuções formais da modalidade oral - a de que as concessivas na posição à direita se caracterizam por acrescentar "outros conteúdos ou argumentos a um segmento linguístico aparentemente concluído". Vale destacar que essa é a ordem não marcada. Neves (1999c) esclarece que, dado o esquema concessivo - refutação a uma objeção/asseveração, a ordem mais adequada desse padrão oracional pareceria corresponder à da anteposição da concessiva. Por outro lado, ressalva que "é bastante plausível que seja mais natural primeiro asseverar-se algo, para depois se prover 'defesa' do ponto de vista expresso". Nesses casos, a concessiva funciona como adendo, de modo que o usuário da língua enuncia, a posteriori, as possíveis objeções a uma proposição que fora enunciada.

Nas adverbiais concessivas, evidencia-se outro tipo de iconicidade a iconicidade relativa às funções discursivas, o que decorre da presença do componente argumentativo. Segundo Neves et al. (2008, p. 979), isso se justifica pela existência de duas etapas no pensamento concessivo: "a elaboração de uma hipótese de objeção por parte do ouvinte e a refutação dessa objeção". Referindo-se à ordem de ocorrência dessas orações, Neves 
(1999c, p. 589) afirma que, quando antepostas, elas atendem à função de tópico das construções em que ocorrem, como comprovam os excertos:

(5) "Não se está advogando aqui que Serra dê um carrinho, que Marina faça jogo perigoso ou que Dilma tente um golpe de mão. Campanhas sem golpes baixos são uma homenagem ao jogo democrático, embora o presidente Lula já tenha sido multado tantas vezes por violar o regulamento eleitoral que, se houvesse cartão vermelho por reincidência, ou se nossos juízes tivessem peito, ele já teria sido expulso da margem do campo. Sem ser candidato, é o único com carisma - e, por isso, ventríloquo de Dilma.

Se os debates eleitorais continuarem assim, previsíveis e cheios de PAC, UPA e UPP, só temos uma saída: Mano para presidente". (ÉP, A, $16 / 08 / 2010)$

(6) “[...] Ao vencer os prussianos, liberou e tratou com grande consideração um grupo de prisioneiros suecos. Sem que $\emptyset$ pudesse saber, isso mudou o seu destino" (VJ, A, 27/10/10)

Quando pospostas, assumem a função de adendo, como mostram os exemplos abaixo:

(7) “[...] Foi-se o tempo em que para roubar muito o indivíduo tinha de mandar muito; hoje em dia qualquer vereador do interiorzão pode ficar milionário em dois tempos, e sem sair do perímetro municipal". (VJ, A, 29/09/10)

(8) “[...] A emergência do Brasil no cenário internacional ocorre em um momento de declínio da influência dos Estados Unidos e do fim de uma ordem internacional unipolar dominada pelos americanos, mas sem que um modelo alternativo esteja pronto para tomar o lugar. [...]" (ÉP, A, $20 / 12 / 10$
E, se intercaladas, "contribuem para a topicalização de elementos da oração nuclear":

(9) "[...] Nesse caso, o eleitor pode vir a comprar gato por lebre. 0 ideal seria que os brasileiros que vão receber os candidatos em sua casa, mesmo sem tê-los convidado, fossem brindados com programas propagandísticos, mas não enganosos". (VJ, CL, 18/01/10)

(10) "[...] O Brasil termina 2011 protagonizando um papel internacional jamais vivido em sua história e até bem pouco tempo atrás impossível de ser imaginado por seus mais otimistas pensadores. Superamos, sem que houvesse qualquer ruptura institucional, a era em que recebíamos de organismos como o FMI e das autoridades financeiras do Velho continente um receituário impondo regras de bom funcionamento. [...]" (IÉ, Edit., $07 / 12 / 11)$

Nos dados coletados, a ordem das orações que consideramos concessivas é variável, mas predomina a posposição; assim, no conjunto das 108 (cento e oito) ocorrências introduzidas por sem + verbo no infinitivo (estrutura reduzida), 80 (oitenta) se apresentam pospostas à matriz; 16 (dezesseis) antepostas e 12 (doze) intercaladas; e, dentre as 23 (vinte e três) ocorrências introduzidas pela locução sem que (estrutura desenvolvida), 19 (dezenove) vêm pospostas; 3 (três) antepostas e 1 (uma) intercalada. Logo, a anteposição e a intercalação em relação à matriz correspondem à ordem marcada.

Em se tratando das orações condicionais, que, à semelhança das concessivas, são passíveis de movimentação, a ordem neutra corresponde, segundo Neves (1999b) e Neves et al. (2008, p. 968), à anteposição da oração condicional (ou prótase) em relação à principal (apódose), explicação também baseada na noção de iconicidade lógico-semântica. Está aí o princípio 
de que primeiramente se enuncia um estado de coisas como condição a ser atendida para depois se enunciar o efeito ou a consequência resultante do que foi enunciado. Os autores acrescentam que a não factualidade da apódose também tem relação com o princípio da iconicidade, envolvendo uma relação causa-efeito; assim, a causa, que é decorrente de uma condição, é enunciada antes do efeito. Esse raciocínio pode ser aplicado ao excerto abaixo:

(11) “Isto É - É possível eliminar o tráfico?

Barreto: Sem acabar com o consumo, a oferta vai sempre tentar suprir a demanda. É claro que, se houver dificuldade, o preço sobe. E aí a tendência é cair o consumo de droga no País. [...]" (IÉ, E, 05/05/10)

em que a diminuição/eliminação ou não do consumo é determinante da baixa ou alta de preço das drogas e, consequentemente, da sua oferta ou não no País. Cabe destacar que o fato de as orações condicionais "constituírem a moldura de referência em relação à qual a principal é verdadeira (se for uma proposição) ou apropriada (se não for)" leva ao entendimento de que funcionam como tópico (CHAFE, 1976, apud NEVES, 1999b). Na sequência, apresentamos um excerto em que a oração condicional se apresenta após a principal, que é a posição mais evidenciada no corpus em estudo.

(12) "A senhora diz ser contrária às privatizações. Mas [...] Não é incoerente se dizer contra as privatizações sem analisar os resultados das empresas antes e depois de privatizadas?" José Caetano Justino - Cipotânea, MG (ÉP, E, 01/11/10)

Nos dados sob análise, das 27 (vinte e sete) ocorrências de orações condicionais reduzidas, apenas sete aparecem antepostas. No caso das estruturas desenvolvidas, as duas ocorrências registradas são pospostas, de modo que a anteposição corresponde à ordem marcada.

Do exposto nas tabelas, podemos afirmar que existe, sim, uma relação entre o sentido expresso pelas orações adverbiais e a ordem de ocorrência na estrutura do período, como ficou evidente nas orações consecutivas e modais, que motivaram a posposição. Por outro lado, considerando-se que a posposição foi a ordem preferida, mesmo nos casos em que a mobilidade era viável, contrariando, inclusive, a tese de que orações condicionais e concessivas são mais recorrentes na primeira posição, deduzimos que as funções discursivas podem estar influenciando a distribuição das orações, aspecto abordado a seguir, no âmbito da interação comunicativa.

\section{Orações adverbiais e o planejamento discursivo: funções textual-discursivas do plano discursivo fundo}

Pezatti (1994), ao abordar a ordem dos constituintes, esclarece que, dependendo do tipo de verbo presente na sentença - se transitivo, intransitivo existencial ou intransitivo não-existencial, há duas ordens naturais e não marcadas: SV (O) e VS. Mas não só aspectos categoriais definem o modo de organização dos constituintes, também fatores pragmático-discursivos estão envolvidos nesse processo. A autora, reportando-se a DeLancey (1981), afirma que uma sentença descreve um evento real ou imaginário, e quando isso ocorre, os papéis dos participantes no universo do discurso são definidos, formando um padrão ou cenas prototípicas. Por outro lado, no âmbito comunicacional, os elementos que constituem o evento não têm a mesma importância, o que se deve à intervenção de dois fatores - o fluxo de atenção e o ponto de vista, parâmetros que "contribuem para determinar o interesse relativo de várias entidades envolvidas no evento real" (PEZATTI, 1994, p. 43). Essas duas noções são de natureza psicológica e refletem estratégias 
perceptuais, mas também podem se aplicar a mecanismos linguísticos; por isso, podem existir duas ordens: uma natural e uma linguística.

A ordem natural, segundo Pezatti (1994), tem relação com a ordenação temporal de fases do evento, devendo os SNs na sentença estar organizados de modo a repeti-la. Se o fluxo de atenção linguístico não reproduz o fluxo de atenção natural é porque houve interferência de motivações especiais, tornando o fluxo de atenção linguístico fortemente marcado. A trajetória do fluxo de atenção linguístico é da esquerda para a direita, de modo que o elemento considerado o ponto de partida corresponde ao tópico (ou a origem, na perspectiva da ordem natural) e o elemento seguinte, o objetivo, corresponde ao comentário (ou à meta na ordem natural). Mesmo quando o verbo é intransitivo, em que não existe um ponto de origem, mas apenas a meta, preserva-se a ordem natural, sendo a meta o ponto final. Nesse caso, a sentença apresenta o comentário ou o objetivo do discurso.

As duas ordens mencionadas correspondem a um dos mecanismos gramaticais capazes de indicar o relevo discursivo ${ }^{6}$, ou seja, identificar uma sentença como figura e outra como fundo. Um trabalho cuja meta seja a investigação dos graus de fundidade das orações requer a observação acurada, seja do tempo e do aspecto verbais ${ }^{7}$, seja da transitividade da sentença, seguindo a proposta de Hopper e Thompson (1980); por outro lado, os resultados da pesquisa realizada por Araújo e Freitag (2012) apontaram que a categoria tempo/aspecto não teve influência na delimitação figura/

\footnotetext{
${ }^{6}$ A esse mecanismo somam-se outros: uso de partículas discursivas em pontos estratégicos que sinalizem para o ouvinte que a oração corrente ou subsequente é fundo ou figura; configuração de paradigmas verbais (tempo e aspecto) e ainda o grau de transitividade da sentença. Esse último recurso é apontado por Hopper \& Thompson (1980), que concebem haver estreita relação entre o relevo e o grau de transitividade da sentença.

7 Os trabalhos que tratam de figura/fundo, segundo Travaglia (2002, p. 79), condicionam essa relação ao aspecto, ao tempo ou ao modo verbal. Assim, esse contraste "seria sempre função das formas e categorias verbais". Por outro lado, na ańlise de textos do português falado, esse autor procura avaliar c relevo, atentando para o desenvolvimento do tópico discursivo, já que o contraste figura/fun estaria ligado à relevância temática.
}

fundo, nos textos de opinião, devido à inexistência de padrões sistemáticos que determinassem sua codificação, pois, como afirmado, o predomínio da forma verbal no presente termina por inviabilizar a delimitação dos planos discursivos. Ou seja, esse parâmetro não serve como critério para marcar os planos em textos dessa natureza, motivo pelo qual não nos detemos nesse aspecto.

Uma característica das orações adverbiais que permite ativar a discussão em torno da mobilidade posicional é a de constituir-se como opção organizacional do discurso, propriedade esta responsável pela distinção desse modelo oracional, também referido por hipotaxe, em relação às orações completivas e adjetivas restritivas. Conforme Decat (2011), a abordagem das funções discursivas das orações adverbiais representa uma busca de incorporar à análise linguística o componente pragmático, ladeando os componentes sintático e semântico. Assim, nesta seção, procuramos demonstrar que, no processo de organização das ideias, o usuário da língua, face à intenção de ser coerente, atenta não apenas para a microestrutura textual, mas também para a macroestrutura, ou o nível discursivo, de modo a viabilizar a compreensão do texto. Comungam com essa visão Haiman \& Thompson (1984, apud DECAT, 2001, p. 148), segundo os quais a mobilidade das orações adverbiais se explica em função "da iconicidade em termos da ordem dos eventos e em termos das funções discursivas" (grifo dos autores citados), estando as opções organizacionais condicionadas à intenção do falante ao transmitir a mensagem.

No que concerne particularmente à função de organização textual, Azevedo (2002), apoiando-se nas conclusões a que chegaram Thompson (1985) e Chafe (1984), afirma ser essa uma atribuição das orações antepostas. E acrescenta, reportando-se a Givón (1993), que as orações antepostas ao mesmo tempo em que servem para introduzir um período, mantêm um vínculo com a porção textual antecedente - caráter de projeção 
e retomada que, nos termos de Azevedo (2002), diz respeito a uma função coesiva, referida por Givón (1993) pela denominação "ponte de coerência", dada a ligação entre duas porções textuais.

Do cotejo das proposições relacionais ${ }^{8}$ e as possibilidades de colocação das orações satélites, Decat (2011) identificou certa regularidade de ordenação, concluindo que, enquanto certas proposições relacionais são propensas a localizar um evento no tempo e no espaço, outras têm a função de orientar discursivamente o interlocutor, seja para a porção antecedente seja para a porção subsequente no texto. Mas alerta que há situações em que o reconhecimento das proposições não é suficiente para explicar a posição das orações. Significa que não necessariamente há uma correspondência entre o tipo de relação semântica envolvida na articulação e a ordem, razão por que se faz necessário investigar a que funções discursivas a oração adverbial está servindo9.

Na reflexão ora realizada não há interesse de delimitar os graus de fundidade das orações sob análise. Partindo do pressuposto de que tais orações, por funcionarem como satélite, constituem prioritariamente fundo - ainda que a essa característica se agreguem as funções de tópico, de adendo, enfim, funções que sinalizam também papel coesivo -, interessa-nos identificar as funções textual-discursivas por elas assumidas.

Conforme Decat (2011), as orações satélites exercem papel preponderante no planejamento textual, pois, dependendo do propósito

\footnotetext{
${ }^{8}$ Entenda-se por proposições relacionais o significado inferido da combinação entre partes do texto. Vale salientar, retomando Decat (2011), que as porções do enunciado que mantêm qualquer dos tipos de relação - tempo, condição, concessão, etc. - não se apresentam necessariamente sob a forma oracional. No enunciado: "Leite com manga, morre", independentemente da presença de um verbo e e um conectivo na primeira porção do texto, é possível inferir da combinação entre as partes do texto uma proposição relacional de condição.

No estudo realizado por Azevedo (2002) relativamente às orações adverbiais finais, as funções discursivas identificadas pelo autor foram as de resumo, conclusão, comentário/ressalva e comprovação. Em se tratando das oraç̃es intercaladas, afirma o autor que, tanto quanto as antepostas, elas podem agregar mais de um sentido; duas funções foram apontadas: ressalva e justificativa.
}

comunicativo, elas podem atender a uma função mais geral, atuando como moldura, ou seja, como informação necessária à compreensão da informação expressa na oração-núcleo, a qual se nomeia fundo. Orações que se prestam a essa função de base ocorrem com frequência na posição posposta, podendo ainda vir intercaladas, agregando a função de avaliação, muito comum nas orações concessivas. Vale ressaltar que outras funções, tais como as de guia, de ponte de transição ${ }^{10} e$ ainda a de tópico, que ocorrem na posição anteposta, não deixam de se caracterizar como fundo. Como essas categorias funcionais têm forte representatividade nos dados coletados para análise, passemos à exposição dos fragmentos textuais ilustrativos de cada uma delas, iniciando pela função de guia, representada, sobretudo, pelas orações antepostas, a exemplo de (13) e (14):

(13) [...] Numa luta sem tréguas contra a marginalidade, implantando de maneira planejada e sistemática, as chamadas Unidades de Polícia Pacificadora (UPPs), o Rio de Janeiro está fazendo história pelos morros e vielas antes dominados por organizações criminosas. Com a operação do último domingo, sem disparar um tiro sequer ou derramar sangue, o poder público fluminense resgatou um dos maiores polos de desigualdade social do país, abandonado há décadas por sucessivos governos. [...] (IÉ, Editorial, 23/11/11)

(14) [...] Olhando para trás, de preferência nos livros de Elio Gaspari sobre a história da ditadura, fica evidente que ela trincou definitivamente em 1977, quando o presidente Ernesto Geisel, no feriado de 12 de outubro,

10 "Ponte de transição" e "Ponte de coerência" são nomenclaturas que reportam à função de organização " sendo cosiva; Det (2011) utiliza a expressão "coesão discursiva” justificando que é o discurso como

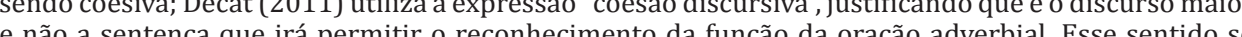
aproxima do valor atribuído por Givón (1993). 
demitiu o general Sylvio Frota da dupla função de ministro do Exército e candidato dos quartéis a sargento-mor do regime.

Sem que os políticos dessem um pio ou as ruas se manifestassem, rompeu-se ali seu condão de perpetuar o regime. Perdendo o poder de sagrar presidentes, o Exército deixou de mandar na República. (IÉ, A, 29/09/2010)

Sob o critério semântico, as duas situações ilustradas evidenciam relações que consideramos concessivas; mas, sob o parâmetro pragmático, são orações utilizadas com o propósito de preparar o leitor em relação à informação subsequente, ou seja, de guiar a interpretação. Nesses dois fragmentos, as orações antepostas têm uma propriedade comum - situam os acontecimentos, atuando como cenário. Em face do propósito de mostrar que a solução dos fatos descritos na oração nuclear ocorreu de maneira pacífica - seja a operação das Unidades de Polícia Pacificadoras, quando do confronto com traficantes nos morros da Rocinha, no Rio de janeiro, em (13), seja a perda de poder do Exército em (14), as orações adverbiais são antecipadas como forma de comprovar o que se afirma na oração nuclear. Ainda na posição anteposta, também a função de ponte de transição é visível nos dados, como demonstra o fragmento abaixo:

(15) “[...] Essas perguntas conduzem-nos, inevitavelmente, a duas conclusões fundamentais. Primeiro, e principalmente, fica claro que já passou da hora de mudar o sistema cujo funcionamento propicia todas essas distorções. Pois não é admissível que um país do tamanho, complexidade e nível de desenvolvimento do Brasil continue sendo administrado por caciques políticos sem preparo, competência ou conhecimento específico, muito mais empenhados em fortalecer suas máquinas partidárias para a próxima eleição do que em preparar o país para a próxima geração. [...]
Sem querer aliviar em um grama sequer o peso da primeira conclusão, é preciso admitir que não é nem justo nem inteligente atribuir todos os problemas nacionais a um punhado de políticos em Brasília. É ingênuo acreditar que bastaria aprovar algumas leis adicionais para resolver todos esses avanços. (VJ, CL, 28/12/11)

Como podemos ver, ao mesmo tempo em que a oração anteposta introduz um novo tópico, viabilizando a progressão temática, ou seja, assumindo uma função catafórica, mantém um vínculo semântico com a porção textual antecedente - que, muitas vezes, não é uma sentença, mas um ou mais parágrafos. Nesse fragmento, a ideia que perpassa todos os parágrafos diz respeito à necessidade de mudança no sistema de ocupação de cargos na administração pública, sob o argumento de que o país está sendo comandado por políticos incompetentes que procuram se manter no posto com o interesse de fortalecer as máquinas partidárias na eleição. Provavelmente no intuito de preservar sua face, o escritor introduz um novo tópico que direciona para a reflexão em torno do problema apontado, numa esfera mais ampla, e não apenas no âmbito político; antes, porém, de apresentar a oração nuclear "é preciso admitir...", ele faz uma ressalva, por meio da oração adverbial anteposta, que, embora sinalize para a atenuação da acusação feita, revela sua insatisfação. Logo, a oração anteposta atua em duas direções - retrospectiva e prospectivamente. Esse atributo da oração anteposta de promover mudança no fluxo informacional, seja para introduzir uma informação totalmente nova ou um desdobramento da anterior, é o que a caracteriza como tópico.

Paralelamente a essa função de tópico, Decat (2011) apresenta a função de foco, que consiste em pôr em destaque um determinado segmento da estrutura oracional. Conforme a autora, a informação saliente concretiza-se como "realce, avaliação, ênfase, argumentação, etc." (DECAT, 2011,p. 144). 
Segue um excerto, dessa vez com oração intercalada, que constitui um acréscimo informacional - seja um reparo, seja um esclarecimento, incidindo sobre um alvo.

(16) Como melhorar a educação num país onde, na fase mais importante da educação para as crianças, os professores - sem desmerecer nenhuma profissão - ganham menos que uma diarista? Rubiano de Lara - Turvo, PR (ÉP, E, Ed. esp. - 01/11/2010)

No questionamento formulado em (16), provavelmente, o entrevistador tem o propósito de valorizar a profissão de professor; mas, considerando que, ao tomar como parâmetro outra profissão, pode ser mal interpretado, por passar a impressão de estar avaliando uma profissão como sendo mais importante que outra, ele insere uma informação que traz um reparo, de modo a realçar a igualdade de valorização de toda e qualquer profissão.

Tanto quanto as orações intercaladas, orações pospostas também podem realçar um elemento da oração matriz. Algumas vezes, o emprego de partículas que denotam oposição ${ }^{11}$, a exemplo do conector "mas", ou o emprego do demonstrativo anafórico "isso" reforçam essa característica, favorecendo o reconhecimento dessa função. Situações semelhantes ocorrem no corpus em análise. Observemos o excerto a seguir:

(17) [...] Há vários tópicos que poderiam ser listados como possíveis propostas de reformulação institucional contra os comportamentos antirrepublicanos. [...] O segundo tópico é discutir melhor o conceito de imunidade parlamentar. É preciso propor uma reformulação jurídica que garanta

${ }^{11}$ É oportuno frisar que Azeredo (2000, p. 250), ao elencar as diversas funções do "mas", atentou para a função focalizadora desse item diante da expressão de circunstâncias. Nas palavras do autor: "O mas pode ainda ser usado como meio de focalização (v. § 366) de uma circunstância: Entre, mas sem fazer barulho (Cf.: Entre sem fazer barulho)". a liberdade do mandato para aqueles que foram eleitos, claro, mas sem que isso se transforme em garantia de impunidade para quem cometeu crimes. Eis um tópico mais relevante e democrático do que propor a pena de morte aos políticos como estava escrito num cartaz exposto no comício do Rio de Janeiro dias atrás. Só faltou pedir a volta da ditadura. (ÉP, A, 26/09/11)

Nesse excerto, ao discutir a proposta de reformulação jurídica, o usuário defende a liberdade de mandato para os candidatos que foram eleitos, destacando um aspecto quanto ao que se deve entender por "liberdade de mandato", ou seja, que "isso" não implique em garantia de impunidade para quem cometeu crimes. Convém esclarecer que o procedimento de focalização não está condicionado ao uso do "mas"; a oração adverbial, em (18), expressa negação de consequência; mas do ponto de vista pragmático serve ao propósito de justificar uma decisão tomada:

(18) Falcão - A decisão do diretório nacional, por 60 a 15 e duas abstenções, acolheu o pedido de filiação, sem que isso significasse anistia nem tampouco correção da decisão anterior. Ele foi punido pelos erros políticos que cometeu e o diretório avaliou que Delúbio tinha cumprido prazo suficiente para que pudesse se filiar, [...] (IÉ, E, 11/05/2011)

Logo, a aceitação do pedido de filiação do parlamentar, na visão do entrevistado, deve-se ao fato de aquele já ter sido punido pelos erros cometidos, e não que tenha havido alteração na decisão anterior.

Além do caráter enfático das orações focalizadoras, é possível depreender nessas orações uma avaliação por parte de quem fala/escreve, pois, conforme já afirmado, as funções comunicativas não são excludentes, tanto é assim que a focalização é uma característica que permeia as orações adverbiais 
que funcionam como parênteses - as chamadas orações parentéticas ou desgarradas.

Esse tipo de estrutura, que passamos a ilustrar a seguir, caracteriza-se por apresentar um fraco vínculo sintático em relação ao enunciado antecedente ou consequente, razão de Decat (2011) afirmar que são "estruturas tidas como subordinadas e que ocorrem sem a matriz, como um enunciado independente". São orações que, segundo a autora, constituem uma unidade informacional; logo, correspondem a um ato de fala por si. Por isso, atuam como adendo, trazendo uma informação adicional, um novo argumento que reforça uma informação anteriormente expressa.

Conforme Decat (2011), as orações que mais ocorrem como "desgarradas" são as causais e as concessivas, sobretudo essas últimas, que trazem normalmente uma avaliação. Além disso, a posição é um fator determinante para a compreensão dessas estruturas, tanto que causais e concessivas, quando pospostas, "já são, acredita-se, um indício de 'desgarramento."” (DECAT, op. cit., p.150). Na escrita, esse tipo de estrutura ocorre após uma pontuação de final de enunciado. Seguem algumas ocorrências desse modelo estrutural.

(19) [...] Júlia também dirigiu Budrus, que registra como um vilarejo palestino de 1.500 habitantes resistiu pacificamente ao muro planejado por Israel. A cerca dividiria o cemitério ao meio, destruiria 3 mil oliveiras e ficaria a 40 metros da escola. Jovens ativistas israelenses e europeus aderiram ao movimento. E Israel mudou o muro de lugar depois de 55 manifestações ao longo de um ano. [...] Em Budrus, a cena mais tocante acontece quando a menina Iltezan, de 15 anos, se joga no buraco feito pela escavadeira do trator e ali se senta, pequena e impassível, diante da máquina. Iltezan arriscava a vida para defender as oliveiras. Sem jogar uma pedra, uma granada. (ÉP, A, 26/09/11)
(20) Temas polêmicos são discutidos. É hora de falar de valores, compartilhar verdades, mesmo incômodas. De preferência, com o celular desligado! Sem tuitar, sem dispersar. A indiferença com o outro me parece hoje um grande desagregador familiar. 0 vício da conexão nos desconecta uns dos outros dentro do que um dia se chamou de lar. (ÉP, A, 20/12/10)

Em (19), há o interesse em criticar atos de violência praticados em manifestações em prol de direitos reivindicados; para tanto, o escritor apresenta uma informação sob a forma de adendo, em que destaca exatamente uma atitude pacífica. Em (20), ao se referir à necessidade de discussão de temas polêmicos, o escritor defende o diálogo como a forma mais efetiva de realização, um meio de aproximar as pessoas, deixando implícita a ideia de que a forma como as discussões vêm ocorrendo não é apropriada.

O tipo de relação semântica expresso em (19) é de concessão, e em (20), de modo; mas, em ambos os casos, as informações adicionais trazem uma opinião; logo, têm uma finalidade argumentativa. Seguem outros casos de orações desgarradas concessivas, sob a forma desenvolvida.

(21) "[...] Meninas de 10 a 15 anos postam no Orkut fotos sensuais, detalhes do corpo. Sem que a família saiba. Como preparar os filhos e os estudantes para um mundo em que o sexo se confunde cada vez mais com a pornografia?" (ÉP, A, 19/04/2010)

(22) "[...] A companheirada vai precisar de uma ficha mais ou menos limpa para levar a revolução dos cargos ao quarto mandato seguido - sem que a opinião pública desperte de sua soneca cívica". (ÉP, A, 24/01/11)

Da análise das funções discursivas, percebemos que, ainda que todas elas tenham sido representadas - quer materializada sob a forma reduzida quer desenvolvida -, a função de adendo teve destaque, incorporando a 
função de foco e de avaliação, subfunções que motivaram a posposição, já que primeiramente se expõe um fato e depois se faz a reflexão. Sobre as orações desgarradas, Decat (2011), reportando-se a Mann e Thompson (1983; 1988), afirma haver uma relação de contraste, de modo que o falante/ escritor, através da estratégia de focalização, denuncia uma atitude não positiva em relação ao que foi enunciado na oração nuclear.

\section{Considerações finais}

Neste artigo, aludimos ao fato de a disposição das orações sofrer interferência, seja do tipo de relação semântica estabelecido entre a oração nuclear e a oração satélite (iconicidade semântica), seja da função discursiva desta última (iconicidade discursiva).

Nos dados sob análise, predominaram as orações pospostas em virtude da alta frequência de orações de valor consecutivo, modal, aditivo, além do valor concessivo, que, embora admita mobilidade, tem inclinação para a posposição, dada a função avaliativa. Esta característica das concessivas tem motivação sobretudo discursiva, já que, na condição de adendo, não só dão sustentação às idéias, como permitem a inserção do autor no texto, através de comentários avaliativos, configurando uma marca de expressividade tão característica dos textos argumentativos.

Nossa abordagem privilegiou a relação entre fluxo informacional e a ordem dos constituintes na sentença, para evidenciar o papel das orações adverbiais na organização discursiva. Desse modo, as funções discursivas dessas orações satélites vão influenciando as subfunções ativadoras de direcionamentos interpretativos para as informações veiculadas no texto. Além disso, observamos que o funcionamento das orações parentéticas confirma sua condição de independência apenas no domínio estrutural, uma vez que elas assumem relevante papel na noção de unidade informacional.
Por fim, importa-nos destacar o fato de os transpositores sem/sem que parecerem-nos muito bem acomodados a essa função introdutora do tipo de construção ora cotejado, conclusão que é sustentada tanto pela incidência quantitativa como pela análise dos aspectos textuais e discursivos aqui levados a efeito.

\section{Referências}

ANTONIO, Juliano Desiderato. Estrutura retórica e combinação de orações em narrativas orais e escritas do português brasileiro. In: Estudos Linguísticos, São Paulo, v. 37, n. 1, p. 223-232, jan./abr. 2008

ARAÚJO, Andréia Silva; FREITAG, Raquel Meister Ko. O Funcionamento dos planos discursivos em textos narrativos e opinativos: um estudo da atuação do domínio aspectual. SIGNUM: Estudos Linguísticos, Londrina, n. 15/1, p. 57-76, jun. 2012.

AZEREDO, José Carlos de. Fundamentos de gramática do português. Rio de Janeiro: Jorge Zahar, 2000

AZEVEDO, João Luiz Ferreira de. Consequências discursivas e semânticas da mobilidade das orações finais no português escrito. Revista Univ. Rural. Sér. Ciências Humanas, v. 24, n. 1-2, p. 11-34, jan./jun. 2002.

CASTILHO, Ataliba. Nova gramática do português brasileiro. São Paulo: Contexto, 2010.

CHAFE, Wallace. L. Givenness, contrastiveness, difiniteness, subjects, topics and point of view. In: LI, C. Subject and Topic. New York: Academic Press, 1976.

How people use adverbial clauses. Proceedings of the tenth meeting of the Berkeley Linguistics Society. 1984. p. 437-450.

DECAT, Maria Beatriz Nascimento. Estruturas desgarradas em Língua Portuguesa. Campinas: Pontes, 2011.

DECAT, Maria Beatriz Nascimento et al. Aspectos da gramática do Português: uma abordagem funcionalista. Campinas: Mercado de Letras, 2001.

DeLANCEY, Scott. An interpretation of split ergativity and related patterns. Language, Baltimore, v. 57, n. 3, p. 626-57, 1981. 
FIRBAS, Jan. Some aspects of the Czechoslovak approach to problems of functional sentence perspective. In: DANES, F. (Ed.). Papers on functional sentence perspective. Prague: Academia Publishing House of the Czechoslovak Academy of sciences, 1974.

GIVÓN, Talmy. Functionalism and grammar. Amsterdam/Philadelphia: John Benjamins, 1993.

HALLIDAY, Michael A. K. The place of functional sentence perpective in lhe system of linguistic description. In: DANES, F. (Ed.). Papers on functional sentence perspective. Prague: Academia Publishing House of the Czechoslovaki Academy of Sciences, 1974.

An introduction to functional grammar. 2. ed. London: Edwards Arnold Publishers Ltd., 1994 [1985].

HALLIDAY, Michael A. K.; HASAN, Duqaiya. Cohesion in English. London: Longman, 1976. HOPPER Paul; THOMPSON, Sandra A. Transitivity in grammar and discourse. Language, Baltimore, v. 56, n. 2, p. 251-99, 1980

MATTHIESSN, Christian; THOMPSON, Sandra. The structure of discourse and "subordination". In: HAIMAN, J.; THOMPSON, S. (Ed.). Clause combining in grammar and discourse. Amsterdam: John Benjamins Plublishing, 1988. p. 275-392. http://dx.doi. org/10.1075/tsl.18

MANN, William C.; THOMPSON, Sandra A. Relational propositions in discourse. California: University of Southern California, 1983.

Rhetorical Structure Theory: toward a functional theory of text organization. Text, v. 8, n. 3, p. 243-281, 1988 .

NEVES, Maria Helena de Moura. As construções causais. In: NEVES, M. H. M. (Org.). Gramática do português falado no Brasil. Campinas: Unicamp, 1999a. Vol. 7, p. 461-496.

As construções condicionais. In: NEVES, M. H. M. (Org.). Gramática do português falado no Brasil. Campinas: Unicamp, 1999b. Vol. 7, p. 497-544.

As construções concessivas. In: NEVES, M. H. M. (Org.). Gramática do português falado no Brasil. Vol. 7, Campinas: Unicamp, p. 545-591, 1999c.

NEVES, Maria Helena de Moura et al. As construções hipotáticas. In: ILARI, R.; NEVES, M. H. M. (Orgs.). Gramática do português culto falado no Brasil. Campinas: Unicamp, 2008. Vol. 2.

PAIVA, Maria Conceição. Ordenação de cláusulas causais: forma e função. 1992. Tese (Doutorado) - Universidade Federal do Rio de Janeiro, Rio de Janeiro, 1992.
PAIVA, Maria Conceição. Isomorfismo informacional entre período simples e período composto. Alfa, São Paulo, v. 41, n. esp., p. 127-140, 1997.

PEZATTI, Erotilde Goreti. Uma abordagem funcionalista da ordem de palavras no português falado. Alfa. São Paulo, v. 38. p. 37-56, 1994.

O funcionalismo em linguística. In: MUSSALIM, Fernanda, BENTES, Anna Christina. (Orgs.) Introdução à linguística: fundamentos epistemológicos. São Paulo: Cortez, 2005, p. 165-218.

PEZATTI, Erotilde Goreti; LONGHIN-THOMAZI, Sanderléia Roberta. As construções coordenadas. In: ILARI, R; NEVES, M. H. M. (Orgs.) Gramática do português culto falado no Brasil. Campinas: Unicamp, 2008. Vol. 2, p. 865-932.

THOMPSON, Sandra A. Grammar and Written discourse: initial vs final purpose clauses in English. Text, v. 5, p. 55-84, 1985. http://dx.doi.org/10.1515/text.1.1985.5.1-2.55

TRAVAGLIA, Luiz Carlos. O relevo no português falado: tipos e estratégias, processos e recursos. In: NEVES, M. H. M. (Org.). Gramática do português falado no Brasil. Campinas: Unicamp, 1999. Vol. 2, p. 77-129.

Recebido em 20/04/2015.

Aceito em $03 / 07 / 2015$ 